\title{
Reciprocal transplantations reveal strong niche differentiation among ploidy-differentiated species of the Senecio carniolicus aggregate (Asteraceae) in the easternmost Alps
}

\author{
Karl Hülber $^{1,2} \mathbb{D} \cdot$ Michaela Sonnleitner ${ }^{1} \cdot$ Julian Haider $^{1} \cdot$ Martin Schwentenwein $^{1} \cdot$ Manuela Winkler $^{1,3}$. \\ Gerald M. Schneeweiss ${ }^{1}$. Peter Schönswetter ${ }^{4}$
}

Received: 12 December 2017 / Accepted: 13 July 2018 / Published online: 13 August 2018

(c) The Author(s) 2018

\begin{abstract}
Phenotypic changes conferred by polyploidisation likely alter the ecological niche of polyploids, coming along with differences in performance compared to their diploid ancestors. However, it is largely unknown whether these performance differences remain constant during the life history of plants. Diploid Senecio noricus, tetraploid S. disjunctus, and hexaploid Senecio carniolicus s. str. of the autopolyploid species complex of S. carniolicus (Asteraceae) from the easternmost Alps were reciprocally transplanted to address the following questions: Are there differences in species performances indicating niche differentiation? If so, does the resident or the higher ploid species-which is taller growing and possibly more tolerant against challenging abiotic and biotic conditions-show higher performance? Are performance differences consistent between the early and late life-history stages? Our data suggest that the hierarchy of species performance depends on the life-history stage. For early life-history stages (seeds and seedlings), we mainly observed superior performance of $S$. carniolicus s. str. even on resident sites of the two other species. In contrast, vital rates of adults were predominantly highest for the resident species. The resident site of $S$. carniolicus s. str., which was expected to be environmentally least stressful (i.e., longest growing period, least affected by frost), turned out to be the most selective one, with high mortality and (nearly) no reproduction of the foreign species most likely due to top soil desiccation. Our study illustrates that there may be no clearcut answer to the question if the resident or the higher ploid species shows superior performance in polyploid complexes, but rather suggests that relative performance may depend on life-history stage.
\end{abstract}

Keywords Niche differentiation · Polyploidy $\cdot$ Senecio carniolicus agg. · Vital rates

Karl Hülber and Michaela Sonnleitner have contributed equally to this manuscript.

Electronic supplementary material The online version of this article (https://doi.org/10.1007/s00035-018-0209-2) contains supplementary material, which is available to authorised users.

Karl Hülber

karl.huelber@univie.ac.at

1 Department of Botany and Biodiversity Research, University of Vienna, Rennweg 14, 1030 Vienna, Austria

2 Vienna Institute for Nature Conservation and Analyses, Giessergasse 6/7, 1090 Vienna, Austria

\section{Introduction}

Polyploidisation plays a fundamental role in the evolution and diversification of angiosperms (Soltis et al. 2009). Polyploids and their diploid or lower ploid ancestors frequently differ in morphological and physiological traits (WeissSchneeweiss et al. 2013; Kolář et al. 2017). Their divergence may arise as a direct consequence of genome duplication (Otto and Whitton 2000) and/or be due to subsequent

3 GLORIA Co-ordination, Center for Global Change and Sustainability, University of Natural Resources and Life Sciences Vienna \& Institute for Interdisciplinary Mountain Research, Austrian Academy of Sciences, Silbergasse 30/3, 1190 Vienna, Austria

4 Department of Botany, University of Innsbruck, Sternwartegasse 15, 6020 Innsbruck, Austria 
adaptive evolution (Petit et al. 1999; Ramsey and Schemske 2002). Polyploids often have larger cells and are typically larger than diploids (Sagarin and Gaines 2002), potentially increasing their competitive abilities (Maceira et al. 1993) despite their frequently slower development (Otto 2007). However, the generality of this pattern is debated (Buggs and Pannell 2007; Collins et al. 2011). Furthermore, polyploids have been suggested to exhibit greater tolerance against challenging abiotic and biotic conditions due to higher genetic and biochemical diversity (Comai 2005; Weiss-Schneeweiss et al. 2013) or higher phenotypic plasticity (Hahn et al. 2012).

Phenotypic changes conferred by polyploidisation likely help polyploids to overcome the ecological limits of their diploid progenitors and allow them to colonize new habitats, resulting in an altered ecological niche of polyploids (Stebbins 1971). Thereby, two principle types of niche differentiation between diploids and their polyploid descendants, both coming along with performance differences in particular habitats, can be distinguished. The first are niche shifts, i.e., changes in environmental optima. They imply that adaptive differentiation at the ploidy-level results in the superiority of the resident (i.e., better adapted) cytotype. Niche shifts promote spatial separation and are, hence, a prerequisite for the long-term co-existence of many ploidy-level differentiated taxa (Kolář et al. 2017). Second, polyploidisation may cause an increased ecological amplitude allowing polyploids to occupy a broader range of habitats than diploids (Levin 1983, 2002; but see McIntyre 2012). Such a scenario might support the often hypothesised general superiority of polyploids compared to their di- or lower ploid congeners (e.g., Maceira et al. 1993; Comai 2005; Weiss-Schneeweiss et al. 2013). Thus, polyploids might have distinct and/or broader niches compared to diploids (McIntyre and Strauss 2017), resulting in strongly varying degrees of ecological differentiation ranging from the restriction of cytotypes to different habitats (Lumaret et al. 1987), which evidently promotes spatial segregation (Parisod et al. 2010; te Beest et al. 2012) to differences in the relative abundance of accompanying species (Johnson et al. 2003).

Niche differentiation in heteroploid species has been inferred by observations of natural populations based on sampling in different habitats (Lumaret et al. 1987; Duchoslav et al. 2010), collecting environmental parameters for individuals of the focal species (Mráz et al. 2012), comparing associated vegetation (Felber-Girard et al. 1996; Johnson et al. 2003; Ståhlberg and Hedrén 2009; Sonnleitner et al. 2016) or performance of plants in common garden experiments (Bretagnolle and Thompson 2001; Manzaneda et al. 2012). Recently, species distribution modelling was applied to compare the climatic niches of cytotypes (McIntyre 2012; Godsoe et al. 2013; Glennon et al. 2014; Kirchheimer et al. 2016). Undoubtedly, these approaches have their merits, but they may also face serious caveats. For instance, observational studies might confound competitive displacement with niche differentiation (Mitchell et al. 2009), and common garden experiments as well as modelling approaches cannot cover all potentially relevant environmental conditions of the cytotypes' native habitats (Baack 2005). In that light, only reciprocal transplantations provide direct evidence for differences in the fundamental niche (Soltis et al. 2010) by comparing the local performance. To date, reciprocal transplants have been applied to test for niche differentiation in di-/tetraploid (Flegrová and Krahulec 1999; Baack 2005; Martin and Husband 2013) or di-/hexaploid model systems (Buggs and Pannell 2007; Raabová et al. 2008), but they have rarely been used in polyploid complexes comprising more than two cytotypes allowing for comparisons among polyploid levels (see also Duchoslav et al. 2017; McIntyre and Strauss 2017). In addition, we are not aware of any reciprocal transplantation experiment covering the full life history (from germination to reproduction) of a heteroploid model system.

The Senecio carniolicus Willd. (syn. Jacobaea carniolica (Willd.) Schrank) aggregate comprises the silicicolous alpine perennials Senecio noricus Flatscher, Schneew. \& Schönsw. (diploid), S. disjunctus Flatscher, Schneew. \& Schönsw. (tetraploid), and S. carniolicus s. str. (hexaploid), which occur sympatrically in the easternmost Eastern Alps (Suda et al. 2007; Sonnleitner et al. 2010). The fourth species of this group, the diploid S. insubricus (Chenevard) Flatscher, Schneew. \& Schönsw., is not present in this region (Flatscher et al. 2015). Molecular genetic evidence suggests that the polyploid species are autopolyploid derivatives of S. noricus (Winkler et al. 2017) and that recurrent formation is highly unlikely, which is in line with consistent morphological differentiation (Flatscher et al. 2015) among the species. Consequently, co-occurrence of species-which was frequently observed in various combinations in close spatial proximity (less than one meter; Hülber et al. 2009, 2015; Sonnleitner et al. 2010)—is likely due to secondary contact in the course of the postglacial colonization of the Alps. Reconstruction of ecological niches based on proxies such as Landolt indicator values of the surrounding vegetation (Schönswetter et al. 2007; Hülber et al. 2009, 2015) provided indirect evidence for ecological differentiation between pairs of species. A large-scale survey (Sonnleitner et al. 2016) additionally revealed differences in the realised niches between pure and sympatric populations of all three species, i.e., niche displacement, which is likely due to competitive effects.

Here we assess differences in performance-measured via two estimates of overall fitness and six single vital rates-of diploid S. noricus, tetraploid S. disjunctus, and hexaploid $S$. carniolicus s. str. by reciprocally transplanting seeds and adult individuals among natural populations. 
We focus on the following questions: (1) Are there ploidydependent differences in species performances indicating niche differentiation? (2) Does the resident or the higher ploid species show higher performance refuting or supporting the often hypothesised general superiority of polyploids? (3) Are performance differences consistent between early (seeds, seedlings) and late (adult) life-history stages?

\section{Materials and methods}

\section{Study design}

The study was conducted east of Turracher Höhe (Gurktaler Alpen, Austria) in areas of exclusive occurrence, in the following referred to as resident sites, of diploid S. noricus, tetraploid S. disjunctus, and hexaploid $S$. carniolicus s. str. The resident site of $S$. noricus was situated on a flat, gravelly, windswept plateau to the West of Mt Kaserhöhe (N $46.91162^{\circ}$, E $13.91403^{\circ} ; 2283 \mathrm{~m}$ a.s.1.), that of $S$. disjunctus on the northern slope of Mt Bretthöhe (N 46.91087 ${ }^{\circ}$, E $13.92445^{\circ} ; 2308 \mathrm{~m}$ a.s.1.), and that of $S$. carniolicus s. str. on the southwestern slope of Mt Schoberriegel (N 46.90967, E 13.89500; $2174 \mathrm{~m}$ a.s.1.); all three resident sites are within a maximal distance of $3 \mathrm{~km}$. In a reciprocal design, we transplanted cypselas (termed "seeds" in the following for simplicity) and adult individuals of the three species to each resident site to assess six vital rates (seed germination, seedling establishment, and seedling growth, as well as adult survival, adult growth, and reproduction) and two indices of overall fitness.

\section{Transplantation of seeds}

Mature seeds were collected in late summer 2010 at each resident site as a pooled sample from about 100 mother plants. Because we expected low survival, we did not consider analysing seed families separately.

Germination experiments were conducted in six $1 \mathrm{~m} \times 1 \mathrm{~m}$ plots per resident site. Plots were subdivided by a removable grid consisting of 100 cells of $0.1 \mathrm{~m} \times 0.1 \mathrm{~m}$. For each species, 25 seeds were sown into each of 15 randomly selected cells in each plot in autumn of 2010 (3 resident sites $\times 6$ plots $\times 3$ species $\times 15$ cells $\times 25$ seeds $=20,250$ seeds). In addition, we randomly chose 15 cells in each plot to observe natural background germination. The number of emerged seedlings was recorded in autumn 2011, 2012 and 2013. After the last observation above-ground biomass of living individuals was harvested, oven dried at $60{ }^{\circ} \mathrm{C}$ for 1 week, and the combined dry weight of seedlings of a cell was measured to the nearest $0.1 \mathrm{mg}$. Separate measurements of individuals were not feasible as the seedlings were rarely bigger than $15 \mathrm{~mm}$ in diameter. Tracing the fate of individual seedlings was impossible, because tagging would have entailed a high risk of damaging the tiny plants frequently growing close to each other. The relatively high proportion of germinating seeds together with massive substrate movement (particularly debris and dead biomass) caused oscillations in the number of recorded seedlings in individual cells in consecutive years. Thus, the number of recorded seedlings in cells within a plot was summed up for each species to balance errors in the detection and re-detection of plants. In addition, the slow development of seedlings-the majority possessed only 2-3 leaves even after 3 years of observation-prevented the discrimination of newly emerged plants from older seedlings.

\section{Seed germination}

Because seedlings emerged in the previous years cannot be differentiated from recently germinated ones, seed germination was defined as the number of seedlings divided by the number of sown seeds only in the first observation after sowing. To test for differences in germination between the species in their resident sites on one hand and the foreign species or the control cells on the other hand, Poisson Generalised Linear Models (function "glm" from the library "stats") were used.

\section{Seedling establishment}

Seedling establishment was defined as the temporal trend in the number of seedlings across observations. To test for differences in seedling establishment, Poisson Generalised Equation Estimations (function "geeglm" from the library "geepack", Halekoh et al. 2006) with an auto-regressive correlation structure among annual observations of the same plot relating the number of seedlings to species, the year of observation, and the species $\times$ year of observation interaction were applied.

\section{Seedling growth}

Differences in seedling growth were calculated by means of log-transformed mean dry weights of seedlings within a cell. To this end, Gaussian Generalised Equation Estimations assuming identical correlation among all cells of a plot (i.e., correlation structure "exchangeable" in the geeglmfunction) and weighting cells by the number of seedlings were applied to compare the species. Model selection was done with the function "step". 


\section{Transplantation of adults}

In autumn 2008, 150 adult individuals per species were dug out from their natural populations, 50 of these were transplanted to each resident site of the two other species, and 50 adult individuals were transplanted within their resident site. The ploidy of all transplanted individuals was determined via flow cytometry (FCM) of silica-dried leaf material following Sonnleitner et al. (2010). All transplanted plants were tagged and observed at annual intervals until autumn 2013. Individuals that were dead at the first observation in 2009 were excluded from all analyses to minimise confounding effects of transplantation. At each observation, (1) the survival status (dead/alive), (2) variables describing plant size (i.e., number of rosettes, number of leaves, length of the longest leaf, largest diameter of the biggest rosette, and diameter perpendicular to it) to model the biomass in earlier years for subsequent growth analysis, and (3) the number of hyperinflorescences, (i.e., shoots bearing flower heads, termed "inflorescences" in the following for simplicity) as a measure for reproduction were recorded. At the end of the experiment, the above-ground biomass of all surviving transplanted individuals was harvested, oven dried at $60^{\circ} \mathrm{C}$ for 2 weeks, and the dry weight measured to the nearest $0.1 \mathrm{mg}$.

\section{Adult survival}

To compare the survival rates of adults among species, Cox Proportional Hazards regression models (function "coxph" in the library "survival", Therneau 2015) were applied, which relate the time between transplantation and death of individuals (in years) to species. Thereby, individuals still alive in 2013 were included as right-censored data.

\section{Adult growth}

To obtain predictions of the biomass in the previous years, the relationship between the measured size variables and dry weight of adults was estimated by least-squares regression using species, the number of leaves and rosettes, the interaction of number of leaves and rosettes with species, first- and second-order polynomials of both diameters, and the length of the longest leaf amended by a presence/absence transformation of the number of inflorescences as predictors. Variable selection omitted the interaction of number of rosettes with species resulting in a model appropriately fitting the data $\left(R^{2}=0.93, F_{13,298}=311.5, p<0.001\right)$. Prior to running the model, dry weight and the number of leaves and rosettes were log-transformed. Fitted regression models were then applied to predict the dry weight of all individuals at each observation. These predictions were scaled to zero mean and unit variance separately for each species in each resident site to be used as measure of adult growth. This was necessary to balance differences in average plant size among species (hexaploid S. carniolicus s. str. >> tetraploid S. disjunctus $>$ diploid S. noricus, Flatscher et al. 2015). An a priori log-transformation ensured the approximate normal distribution of data. Gaussian Generalised Equation Estimations with an auto-regressive correlation structure among annual observations of the same individual (i.e., "ar1" in the "geeglm"-function of the library "geepack", Halekoh et al. 2006) were applied. These models relate dry weight to species, year of observation, and their interaction. Coefficients and marginal $p$ values of the interaction term indicate whether the changes in dry weight across time differ between species.

\section{Reproduction}

The number of inflorescences in 2009 was about three times higher than that summed up for all subsequent years indicating direct effects of the transplantation. Thus, we omitted data of this year from analyses. To compare the reproduction among the species, we applied Poisson Generalised Equation Estimations (function "geeglm") with an autoregressive correlation structure among annual observations of the same individual. We fitted models with species, year of observation, and their interaction to compare the temporal trend in flowering frequency (indicated by the coefficients of the interaction term). Comparisons including $S$. noricus and $S$. disjunctus in the resident site of $S$. carniolicus s. str. as well as of $S$. disjunctus in the resident site of $S$. noricus were not feasible because of the low number $(0,1,1)$ of inflorescences.

\section{Overall fitness}

As a measure of overall success of a species transplanted (adults) or sown (seeds) to a particular resident site, two fitness indices were calculated. Fitness ${ }_{\text {veg }}$ relates to establishment success and encompasses seed germination as well as seedling and adult survival, and is calculated as: (number of germinated seedlings 2011/number of seeds sown 2010$) \times$ (sum of number of seedlings 2010-2013/ sum of number of seedlings 2009-2012) $\times$ (sum of number of surviving adults 2010-2013/sum of number of adults 2009-2012). Fitness ${ }_{\text {rep }}$ relates to reproductive success and includes also reproduction, and is calculated as fitness $_{\text {veg }} \times$ (sum of number of inflorescences 2010-2013).

All analyses and figures were done using the statistical computing environment R 3.3.2 (R Development Core Team 2016). For an extension of the experiment including plants from other mountain ranges, see Supplementary Material 1. Data are available from the Dryad Digital Repository: https ://doi.org/10.5061/dryad.cq98678. 


\section{Results}

Both indices of overall fitness, fitness ${ }_{\text {veg }}$ and fitness ${ }_{\text {rep}}$, delivered qualitatively identical results (Table 1). Resident species showed the highest overall fitness, except for the

Table 1 Overall fitness of species of the Senecio carniolicus agg. transplanted or sown to resident sites of diploid Senecio noricus, tetraploid S. disjunctus and hexaploid S. carniolicus s. str. (a) fitness $_{\text {veg }}$, index based on seed germination, seedling and adult survival only; (b) fitness ${ }_{\text {rep }}$, index based on seed germination, seedling and adult survival and reproduction

\begin{tabular}{llll}
\hline Transplanted species & \multicolumn{2}{l}{ Resident species } \\
\cline { 2 - 4 } & S. noricus & S. disjunctus & $\begin{array}{l}\text { S. car- } \\
\text { niolicus s. } \\
\text { str. }\end{array}$ \\
& & &
\end{tabular}

\begin{tabular}{llll}
\hline $\begin{array}{l}\text { (a) } \text { Fitness }_{\text {veg }} \\
\text { S. noricus }\end{array}$ & $\mathbf{0 . 1 0 8}$ & 0.168 & 0.023 \\
S. disjunctus & 0.055 & 0.190 & 0.019 \\
$\quad$ S. carniolicus s. str $^{\text {(b) Fitness }}$ rep & 0.085 & $\mathbf{0 . 2 3 0}$ & $\mathbf{0 . 1 1 5}$ \\
$\quad$ S. noricus & & & \\
S. disjunctus & $\mathbf{2 . 1 6 4}$ & 2.685 & 0.000 \\
S. carniolicus s. str & 0.000 & 2.087 & 0.019 \\
\hline
\end{tabular}

Data from several years were pooled for analysis. The best-performing species at a given transplantation site is highlighted in bold resident site of $S$. disjunctus, where $S$. carniolicus s. str. was the best-performing species. Fitness of foreign species was particularly low at the resident site of $S$. carniolicus s. str., and $S$. disjunctus had a low fitness, particularly at foreign sites.

The relative performance of the three investigated species strongly depended on the vital rate considered. Concerning seed germination and seedling growth, S. carniolicus s. str. performed best at all sites: i.e., this species showed the highest number of seedlings in the first year after sowing (Fig. 1, Table 2) and the highest dry weight of emerged seedlings at the end of the observation period (Fig. 2, Table 2). However, at the resident site of S. carniolicus s. str., mean seedling weight of $S$. noricus and $S$. carniolicus s. str. was not significantly different. Mean germination rate at the resident site of $S$. noricus, $S$. disjunctus, and $S$. carniolicus s. str. was $12.7,26.3$, and $10.5 \%$, respectively. Seed germination in control cells was significantly lower than in sown-in cells for all resident species $(S$. noricus: coef $=-2.00 \pm 0.18, z$ value $=-11.24, p<0.001 ; S$. disjunctus: coef $=-2.28 \pm 0.14, z$ value $=-16.29, p<0.001$; S. carniolicus s. str.: coef $=-2.91 \pm 0.22$, $\mathrm{z}$ value $=-13.28$, $p<0.001)$. In general, the number of seedlings decreased throughout the observation period (Fig. 1). This reduction was generally lowest (i.e., seedling establishment was highest) for the resident species, except for $S$. noricus performing better than $S$. disjunctus on the resident site of the latter
Fig. 1 Seed germination (i.e., number of seedlings in 2011) and seedling establishment (change in number of seedlings from 2011 to 2013) of species of the Senecio carniolicus agg. observed at resident sites of diploid S. noricus, tetraploid $S$. disjunctus, and hexaploid $S$. carniolicus s. str. in 2011 (light grey), 2012 (medium grey), and 2013 (dark grey). Underlined names indicate the species to whose resident site individuals were transplanted. The number of seedlings is summed up for each plot
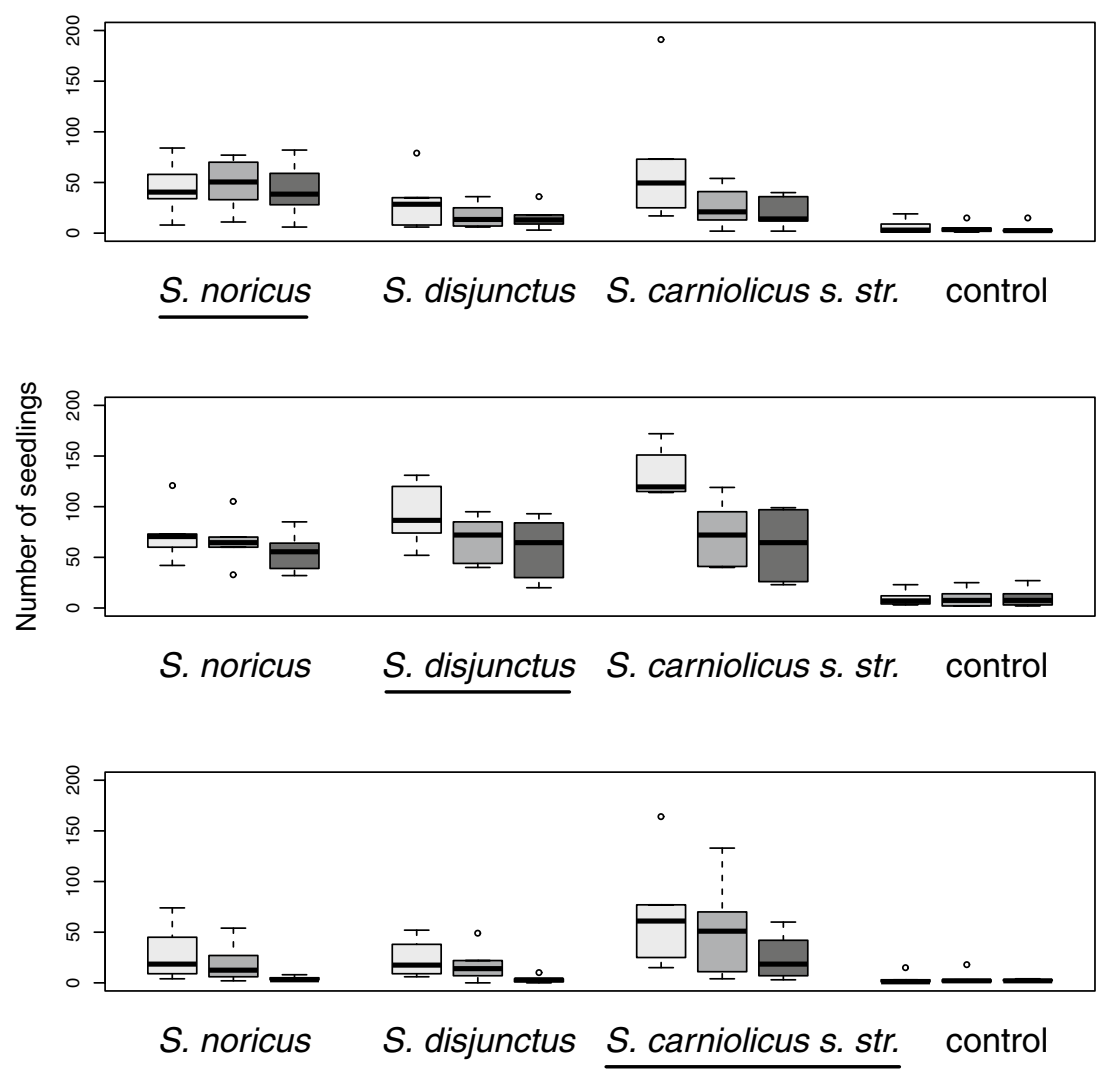
Table 2 Comparison of six vital rates between resident and foreign species of the Senecio carniolicus agg. derived from reciprocal transplantations of seeds and adult individuals into resident sites of diploid
S. noricus, tetraploid S. disjunctus, and hexaploid S. carniolicus s. str. and subsequent annual observations (2009-2013)

\begin{tabular}{|c|c|c|c|c|c|c|c|c|c|}
\hline & \multicolumn{3}{|c|}{ Seed germination } & \multicolumn{3}{|l|}{ Seedling establishment } & \multicolumn{3}{|l|}{ Seedling growth } \\
\hline & Coef $\pm \mathrm{SE}$ & $z$ value & $p$ value & Coef $\pm \mathrm{SE}$ & Wald & $p$ value & Coef \pm SE & Wald & $p$ value \\
\hline Resident $S$. noricus & & & & Scale $=16.50 \pm 7.34$ & & & Scale $=0.32 \pm 0.05$ & & \\
\hline S. disjunctus & $-0.36 \pm 0.10$ & -3.75 & $<0.001$ & $-0.37 \pm 0.06$ & 38.24 & $<0.001$ & $0.09 \pm 0.11$ & 0.59 & 0.443 \\
\hline S. carniolicus s. str & $0.42 \pm 0.08$ & 5.37 & $<0.001$ & $-0.70 \pm 0.15$ & 21.21 & $<0.001$ & $0.47 \pm 0.06$ & 51.76 & $<0.001$ \\
\hline Resident S. disjunctus & & & & Scale $=9.24 \pm 0.85$ & & & Scale $=0.21 \pm 0.03$ & & \\
\hline S. noricus & $-0.23 \pm 0.06$ & -3.59 & $<0.001$ & $0.12 \pm 0.05$ & 6.79 & 0.009 & $0.10 \pm 0.11$ & 0.93 & 0.335 \\
\hline S. carniolicus s. str & $0.36 \pm 0.06$ & 6.55 & $<0.001$ & $-0.19 \pm 0.08$ & 6.63 & 0.010 & $0.27 \pm 0.11$ & 5.55 & 0.018 \\
\hline $\begin{array}{l}\text { Resident } S \text {. carniolicus } \\
\text { s. str }\end{array}$ & & & & Scale $=20.80 \pm 10.30$ & & & Scale $=0.39 \pm 0.13$ & & \\
\hline S. noricus & $-0.87 \pm 0.09$ & -9.48 & $<0.001$ & $-0.58 \pm 0.11$ & 27.12 & $<0.001$ & $-0.07 \pm 0.23$ & 0.10 & 0.746 \\
\hline \multirow[t]{3}{*}{ S. disjunctus } & $-1.05 \pm 0.10$ & -10.78 & $<0.001$ & $-0.33 \pm 0.12$ & 7.58 & 0.006 & $-0.64 \pm 0.24$ & 7.21 & 0.007 \\
\hline & \multicolumn{3}{|l|}{ Adult survival } & \multicolumn{3}{|l|}{ Adult growth $^{\mathrm{a}}$} & \multicolumn{3}{|l|}{ Reproduction $^{\mathrm{b}}$} \\
\hline & Coef \pm SE & $z$ value & $p$ value & Coef \pm SE & Wald & $p$ value & Coef $\pm \mathrm{SE}$ & Wald & $p$ value \\
\hline $\begin{array}{l}\text { Resident } S \text {. noricus; } \\
\quad n=147\end{array}$ & Deaths $=9$ & & & Scale $=0.95 \pm 0.10$ & & & \multicolumn{3}{|c|}{ Scale $=1.44 \pm 1.35(n=96)$} \\
\hline S. disjunctus & $-0.01 \pm 1.00$ & -0.01 & 0.994 & $-0.12 \pm 0.05$ & 5.48 & 0.019 & - & - & - \\
\hline S. carniolicus s. str & $0.95 \pm 0.84$ & 1.14 & 0.256 & $-0.18 \pm 0.05$ & 11.87 & $<0.001$ & $-1.03 \pm 0.33$ & 9.93 & 0.002 \\
\hline $\begin{array}{l}\text { Resident } S \text {. disjunctus; } \\
\quad n=139\end{array}$ & Deaths $=9$ & & & Scale $=0.95 \pm 0.08$ & & & \multicolumn{3}{|c|}{ Scale $=1.04 \pm 1.15(n=138)$} \\
\hline S. noricus & $-0.96 \pm 0.84$ & -1.15 & 0.249 & $-0.10 \pm 0.06$ & 2.89 & 0.089 & $-0.91 \pm 0.37$ & 5.90 & 0.015 \\
\hline S. carniolicus s. str & $-0.78 \pm 0.84$ & -0.94 & 0.349 & $-0.23 \pm 0.06$ & 17.81 & $<0.001$ & $-1.06 \pm 0.45$ & 5.50 & 0.019 \\
\hline $\begin{array}{l}\text { Resident } S \text {. carniolicus s. } \\
\text { str.; } n=123\end{array}$ & Deaths $=71$ & & & Scale $=0.89 \pm 0.17$ & & & - & & \\
\hline S. noricus & $4.30 \pm 0.74$ & 5.85 & $<0.001$ & $-0.69 \pm 0.11$ & 38.84 & $<0.001$ & - & - & - \\
\hline S. disjunctus & $4.12 \pm 0.74$ & 5.60 & $<0.001$ & $-0.58 \pm 0.08$ & 52.91 & $<0.001$ & - & - & - \\
\hline
\end{tabular}

Seed germination, seedling establishment, and seedling growth represent the number of seedlings emerged in 2011, the temporal trend in the number of seedlings from 2011 to 2013, and the mean dry weight of seedlings, respectively. Survival, growth, and reproduction of adult transplants represent temporal trends in the number of living individuals, predicted above-ground biomass, and the number of inflorescences, respectively. Marginal coefficients were derived from Generalised Linear Models (seed germination), Cox Proportional Hazards regression models (adult survival), and Generalised Estimation Equations (other vital rates), and represent either the species term (adult survival, seed germination, and seedling growth) to illustrate differences among species or the year of observation $\times$ species interaction (adult growth, reproduction, and seedling establishment) to illustrate differences in the temporal trend among species. Main effect coefficients for species and year in the latter and the intercept in all models are not presented to enhance clarity. $N=6$ plots per species at each site for all seed and seedling models

${ }^{a}$ Adult weight for annual observations was obtained from a linear regression relating non-destructively measured variables of plant size to plant weight measured after harvest in 2013

${ }^{b}$ Missing values for reproduction are due to low numbers of inflorescences (zero or one)

(Table 2). Seedling survival of foreign species was lowest at the resident site of $S$. carniolicus s. str., with only 24 and 21 seedlings of $S$. noricus and $S$. disjunctus, respectively, surviving until the end of the observation period (Fig. 1). Thus, the low numbers of seedlings in cells sown-in with $S$. noricus and $S$. disjunctus seeds are in the range of the background germination of S. carniolicus s. str.

Resident species outperformed their foreign counterparts in terms of adult growth and reproduction (Table 2). Predicted dry weight of foreign species consistently decreased during the observation period, while that of the resident species remained approximately at the same level as at the time of transplantation (Fig. 3). Similarly, the mean number of inflorescences was either close to zero throughout the observation period or decreased between 2010 and 2013 for foreign species. In contrast, the number of inflorescences increased over time ( $S$. noricus) or remained approximately constant (S. disjunctus, S. carniolicus s. str.) for resident species (Fig. 4). Survival of adults (Fig. 5, Table 2) did not differ among species at the resident sites of $S$. noricus and $S$. disjunctus as survival rates of all three species were $\geq 90 \%$. In contrast, S. carniolicus s. str. strongly outperformed foreign species at its resident site, where not a single and only 


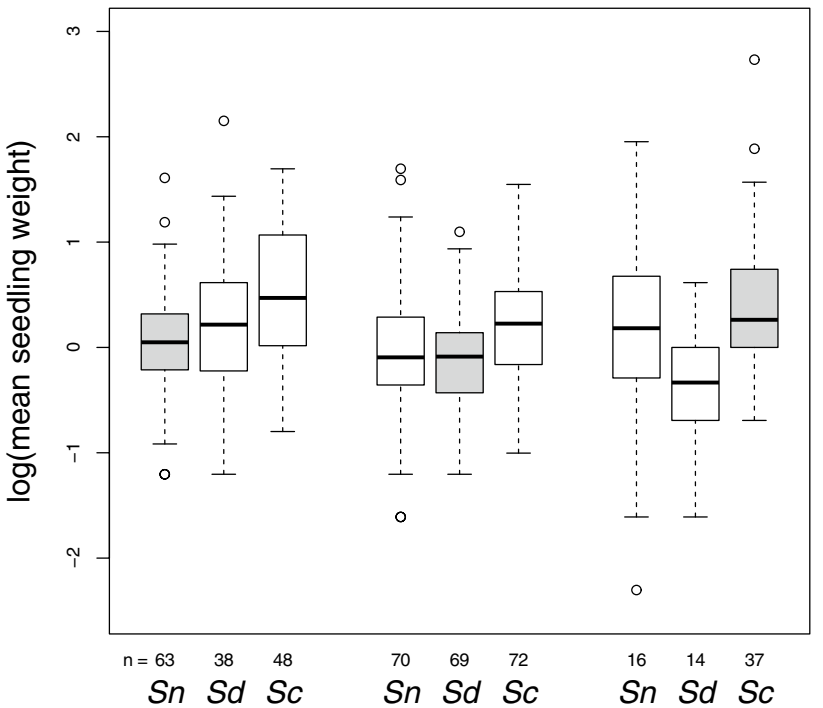

Fig. 2 Log-transformed mean weight of seedlings of species of the Senecio carniolicus agg., indicating the growth 4 years after sowing in resident sites of diploid $S$. noricus $(\mathrm{Sn})$, tetraploid $S$. disjunctus $(S d)$, and hexaploid $S$. carniolicus s. str. $(S c)$. Grey boxes indicate the species to whose resident site individuals were transplanted. $N$ represents the number of seedlings four (8\%) individuals of S. noricus and S. disjunctus, respectively, survived until the end of the experiment.

Not a single individual of $S$. disjunctus flowered in the resident site of $S$. noricus. S. carniolicus $\mathrm{s}$. str. initially performed well there but showed a strong decrease in reproduction between 2011 and 2013 (Fig. 4). Conversely, in the resident site of $S$. disjunctus, the average number of inflorescences of $S$. noricus was high, but decreased from year to year. The resident species, in contrast, showed an approximately doubled reproduction in 2013 compared to the previous years. Reflecting the low survival rates, reproduction of S. disjunctus and S. noricus was zero in the resident site of S. carniolicus s. str. during the last 3 years of the observation period (Fig. 4).

\section{Discussion}

Spatial segregation, as observed within the $S$. carniolicus aggregate (Schönswetter et al. 2007; Sonnleitner et al. 2010, 2016; Hülber et al. 2015) and many other polyploid systems, may result from frequency-dependent selection against rare cytotypes (Levin 1975), the migration history in combination with dispersal limitation (Thompson and Lumaret 1992; Baack 2004), or niche differentiation among species. To test for the latter, we performed reciprocal transplantations
Fig. 3 Growth of adult individuals of species of the Senecio carniolicus agg. reciprocally transplanted to resident sites of diploid S. noricus (above), tetraploid $S$. disjunctus (centre), and hexaploid S. carniolicus s. str. (below). Underlined names indicate the species to whose resident site individuals were transplanted. $N$ represents the number of individuals from 2009 to 2013 (white to dark grey). The $y$-axes represent dry weight of individuals predicted by means of linear regressions from individuals harvested and weighed at 2013 based on annual, non-destructive measurements of size parameters. Dry weight was log-transformed and standardised to zero mean and unit variance separately for each species in each resident site to balance different plants sizes of species. Increases in the number of individuals were caused by missed individuals (overlooked or without aboveground organs in a particular year)
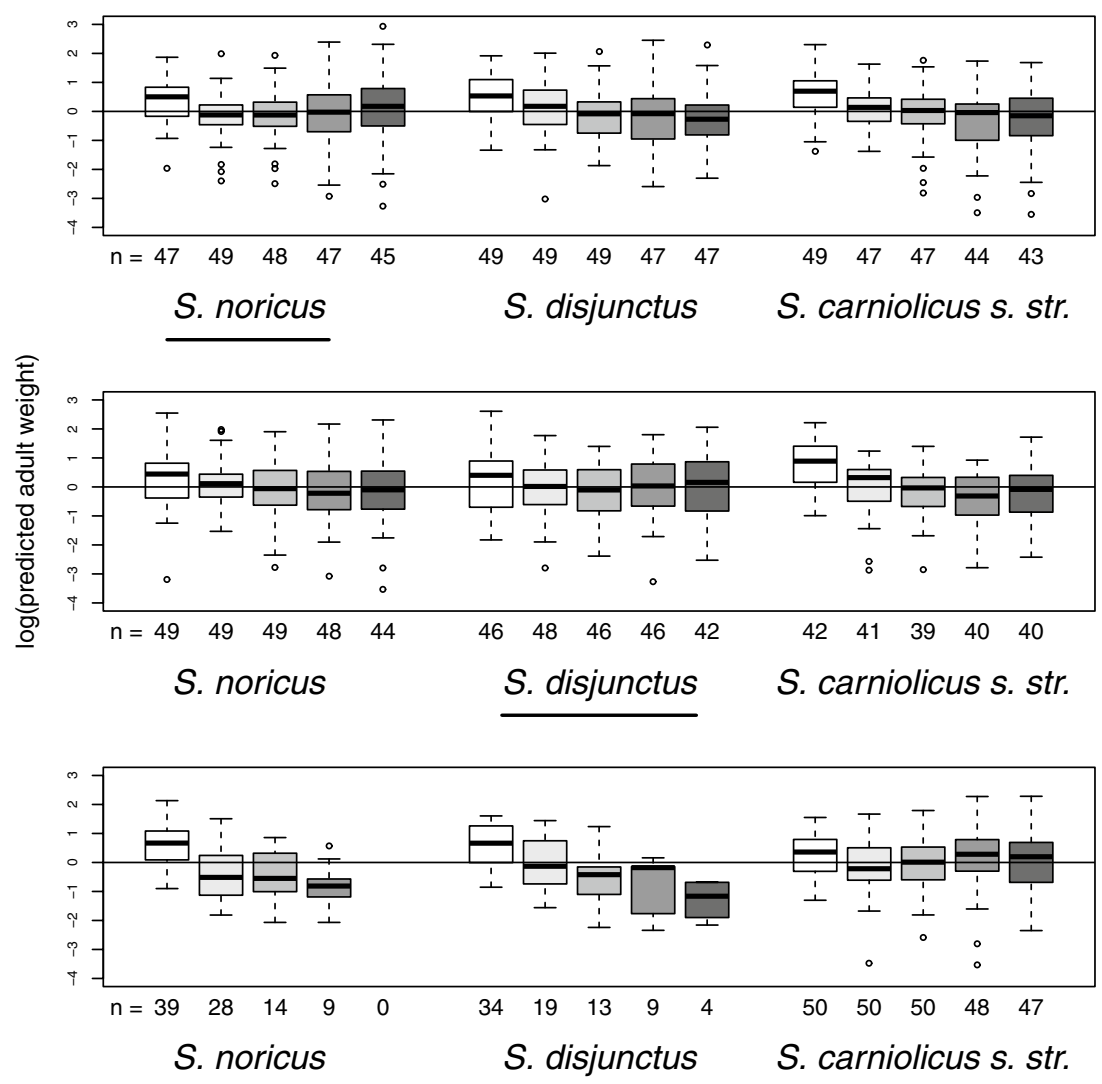
Fig. 4 Reproduction of individuals of species of the Senecio carniolicus agg. reciprocally transplanted to resident sites of diploid $S$. noricus (above), tetraploid $S$. disjunctus (centre), and hexaploid S. carniolicus s. str. (below). Underlined names indicate the species to whose resident site individuals were transplanted. $N$ represents the number of observed individuals from 2010 to 2013

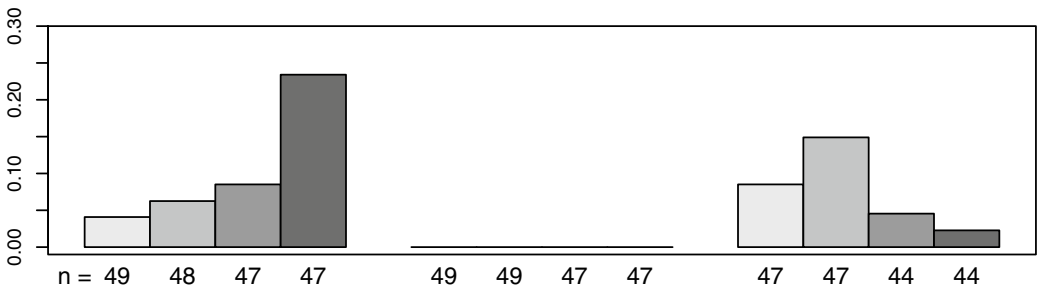

S. noricus

S. disjunctus

S. carniolicus s. str.
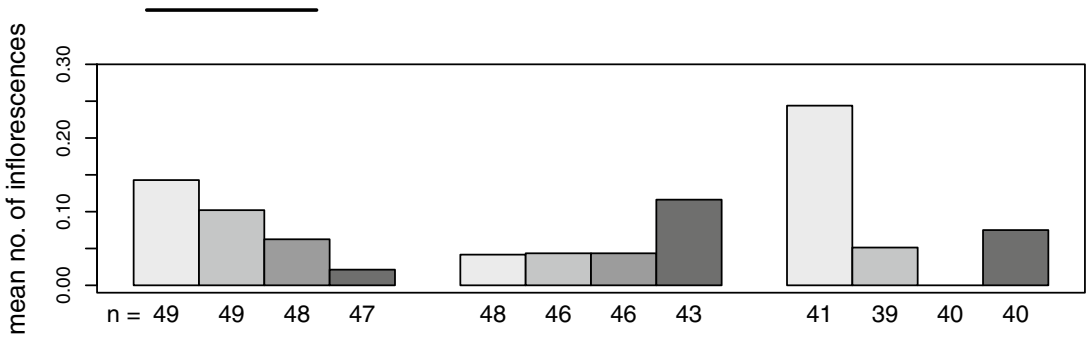

S. noricus

S. disjunctus

S. carniolicus s. str.

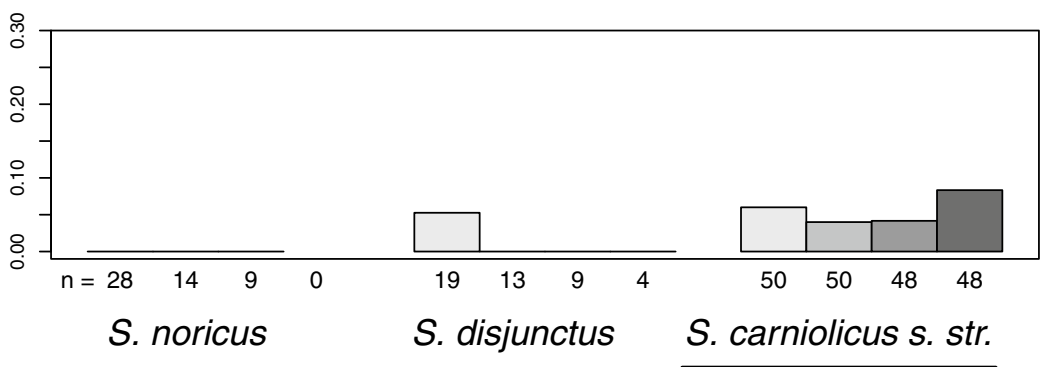

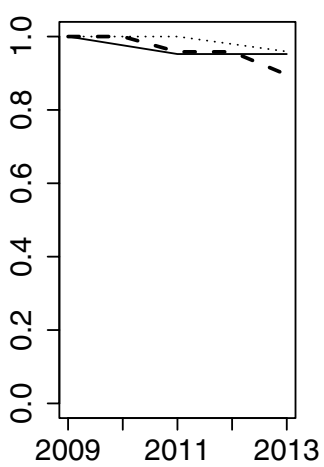

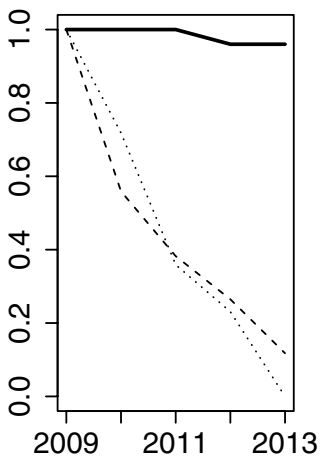

Fig. 5 Proportion of surviving adult individuals of species of the Senecio carniolicus agg. reciprocally transplanted to resident sites of diploid Senecio noricus (left), tetraploid S. disjunctus (centre), and hexaploid S. carniolicus s. str. (right). Dotted, dashed, and solid lines

and measured the performance of the recently delineated diploid S. noricus, tetraploid $S$. disjunctus, and hexaploid S. carniolicus s. str. (Flatscher et al. 2015). Differences in the overall performance as well as in individual vital rates (Tables 1,2) provide direct experimental evidence that these species are ecologically differentiated. This is not surprising, as multi-faceted phenotypic, distributional, and/or environmental differences exist between diploid and autopolyploid represent transplanted $S$. noricus, $S$. disjunctus, and $S$. carniolicus $s$. str., respectively. Underlined names indicate the species to whose resident site individuals were transplanted

populations in almost all the studied systems (Ramsey and Ramsey 2014). Differences in performance demonstrating niche differentiation were particularly found for mixedploidy systems in mountain regions. Diploid Anthoxanthum alpinum was found to occur at higher elevations than tetraploid A. odoratum (Flegrová and Krahulec 1999). Similarly, diploid Chamerion angustifolium performs better at colder, more elevated sites than tetraploid individuals of the same 
species (Martin and Husband 2013; Thompson et al. 2014). In contrast, in Empetrum nigrum (Elvebakk and Spjelkavik 1995), polyploids are more cold-adapted. Consequently, the hypothesis of polyploids being more tolerant against harsh environmental conditions (Levin 2002) cannot be confirmed for all or even the majority of species. Despite the often fundamental role of niche differentiation in the establishment of autopolyploids (Parisod et al. 2010), transplantation experiments revealed no differences between cytotypes in Ranunculus adoneus (Baack and Stanton 2005). In the absence of niche differentiation, the distinct distribution of tetraploids was explained by chance dispersal events.

Most transplantation studies found niche differences among cytotypes to be adaptive, implying that the resident lineage outperforms foreign ones, and identified niche shifts as the predominant process of niche differentiation between diploids and their polyploid relatives. For example, superiority of local ploidy over foreign ploidy levels was shown in experiments involving tetra-, penta-, and hexaploid Allium oleraceum (Duchoslav et al. 2017), di- and hexaploid Aster amellus (Raabová et al. 2008), di- and tetraploid C. angustifolium (Martin and Husband 2013), and di-, tetra-, and hexaploid members of the Claytonia perfoliata group (McIntyre and Strauss 2017). Evidence for a broader niche and, hence, the general superiority of a single cytotype is less strong. A well-known example was provided by Buggs and Pannell (2007): diploid Mercurialis annua showed a consistently higher performance than its polyploid congener-not vice versa as might be hypothesised based on the frequently larger ranges of polyploids (see citation in WeissSchneeweiss et al. 2013). In M. аппиа, diploids are currently displacing polyploids mainly driven by asymmetrical pollen swamping (Buggs and Pannell 2006). Ramsey (2011) recorded a fitness advantage of hexaploid Achillea borealis over tetraploids in parental tetraploid habitats, but reciprocal fitness was not examined. No "home-range" advantage was also detected by Dona and Galen (2007) for C. angustifolium. Individuals of unknown ploidy transplanted within their resident plot had lower survival than those from other plots with no trend concerning distance or elevation.

For the S. carniolicus agg., we found a clear home-range advantage for two out of the three study species. Senecio noricus and S. carniolicus s. str. showed a higher overall fitness and higher vital rates of the transplanted adults than other species at their resident site (Tables 1,2). In contrast, the overall performance of $S$. disjunctus was lower than that of $S$. carniolicus s. str. at its resident site (Table 2). Mechanisms and processes driving this pattern cannot be inferred directly from this study. However, it is likely that the asymmetric gene flow from the tetraploid $S$. disjunctus to the hexaploid S. carniolicus s. str. due to back-crosses of pentaploid hybrids with their hexaploid parents contributes to the competitive weakness of the former (Hülber et al. 2015), as traits relevant for the adaptation to $S$. disjunctus habitats might be introgressed into $S$. carniolicus. However, at the resident site of $S$. disjunctus, both the vital rates of adult plants as well as the overall fitness considering only vegetative traits were maximally as high as those of $S$. noricus. This competitive disadvantage of $S$. disjunctus compared to $S$. noricus might be explained by a more negative effect of transplantation as $S$. disjunctus often grows in coarsegrained scree. This substrate does not allow digging out $S$. disjunctus plants with compact root balls, causing lower performance even if back-transplanted to the resident site.

Most transplantation studies focused on the early lifehistory stages (Baack and Stanton 2005; Buggs and Pannell 2007; Ramsey 2011; Martin and Husband 2013; Duchoslav et al. 2017), while much less empirical evidence is available for adults (Flegrová and Krahulec 1999; Raabová et al. 2008) or the whole life history (McIntyre and Strauss 2017). Our investigation of the $S$. carniolicus group clearly demonstrates that it is important to cover a broad range of life-history stages (e.g., from germination to reproduction), because the pattern of performance differences, from which niche differentiation is inferred, might change during the ontogenetic development. Our data suggest superior performance of polyploids during early life-history stages. Specifically, hexaploid S. carniolicus s. str. outperformed its lower ploid relatives by having higher germination rates in the first year of observation and stronger subsequent growth at all the sites (Table 2). Seedling establishment (i.e., survival through the observation period; Fig. 1) of S. carniolicus s. str., however, was lower than that of $S$. noricus and $S$. disjunctus at their resident sites (Table 2, Fig. 1), which implies a higher mortality rate of S. carniolicus s. str. seedlings. S. carniolicus s. str. is obviously able to establish in foreign habitats, but will likely die out gradually - a pattern already observed in other heteroploid species (Duchoslav et al. 2017). In contrast to seeds and seedlings, a home-range advantage was detected for transplanted adults of all study species. Resident species showed the strongest growth (Fig. 3, Table 2) and the highest reproduction (Fig. 4, Table 2). Thus, the adaptation of niche-differentiated members of heteroploid species or species groups to their local habitats might be much stronger at later life-history stages, while the performance of seeds and seedlings might be mainly determined by species- or ploidy-intrinsic, non-adaptive characteristics (such as larger seeds, see below). Performance differences indicating the lack of adaptation in single vital rates were also observed in other studies (e.g., higher germination of the foreign cytotypes of C. angustifolium in Martin and Husband 2013).

The by far most selective conditions for the survival of early and late life-history stages of foreign species were obviously experienced at the south-exposed, moderately steep resident site of $S$. carniolicus s. str. While adult 
survival rates and seedling establishment of $S$. carniolicus s. str. were in the range of the other species at their resident sites, performance of foreign species was marginal (Figs. 1, 5). This was unexpected as we would have assumed the resident site of S. noricus, a flat kryoturbated terrace with a continuous cover of small stones situated close to a ridge, where strong winds prevent the growth of closed Carex curvula swards, to be the most challenging growing site, followed by the north-exposed resident site of $S$. disjunctus, which is cold, mossy, and instable likely due to occurrence of permafrost-stabilised screes. Anecdotal field observations from the early vegetation period (Sonnleitner and Schönswetter, unpublished field observations) render differences in snow cover, one of the major drivers of small-scale distribution of alpine plants (Körner 2003), unlikely to be responsible for the observed fitness differences. Whereas the resident site of $S$. noricus remains without snow cover for most of the winter, those of S. carniolicus s. str. and $S$. disjunctus experience similar snow cover duration; differences in exposition are apparently compensated by the lee situation of the southexposed site of $S$. carniolicus $\mathrm{s}$. str. Therefore, we suggest that the factor contributing most to the selective growing conditions is top soil desiccation in summer, which was also found to be a major impediment for survival in a transplantation experiment conducted with tetra- and hexaploid $A$. borealis (Ramsey 2011). The weakly continental climate of the investigated area (Gams 1931; Wakonigg 1978), which receives rain shelter from the North (e.g., Niedere Tauern chain) as well as from the South (Julijske Alpe/Alpi Giulie), is likely enforced by southern exposition, relatively open vegetation, and a dark raw humus layer (Turner 1958).

The increased drought tolerance of the early life-history stages of $S$. carniolicus s. str. is probably a ploidy effect, similarly as the species' taller growth (Flatscher et al. 2015) and larger seeds (M. Sonnleitner, pers. obs.). Larger seeds appear to develop into bigger seedlings: the average distance between the tips of the cotyledons (value before the slash) and the average length of the radicula at the time of the unfolding of the cotyledons (value after the slash) are $4.8 \mathrm{~mm} / 3.8 \mathrm{~mm}(n=51)$ in $S$. noricus, $5.0 \mathrm{~mm} / 4.7 \mathrm{~mm}$ $(n=28)$ in $S$. disjunctus, and $6.0 \mathrm{~mm} / 8.2 \mathrm{~mm}(n=36)$ in $S$. carniolicus $\mathrm{s}$. str. The bigger seedlings of the latter may have more resources in terms of water and nutrients to reach constantly humid soil layers; in addition, they might reach these layers earlier due to faster growth (but see Bretagnolle et al. 1995) than seedlings of the two lower ploid species, potentially conferring a crucial selective advantage during the early establishment. Still, it is important to note that at its resident site only half as many seedlings of S. carniolicus $\mathrm{s}$. str. survived as did seedlings of S. disjunctus and S. noricus at their resident sites (Fig. 1). This low probability of establishment might contribute to the lower population densities of $S$. carniolicus s. str. as compared to $S$. disjunctus and especially S. noricus in their respective resident sites (Sonnleitner and Schönswetter, unpublished field observations).

Reproduction exhibited positive and negative temporal trends in resident and foreign sites, respectively (Fig. 4), indicating a strong selective role of the environment. Strong evidence for adaptation in reproductive traits in contrast to vegetative growth has been frequently reported in plants (Bischoff et al. 2006), amongst other in a reciprocal transplantation study comparing vegetative traits of local and foreign cytotypes (Duchoslav et al. 2017). Differential reproductive success may, indeed, explain the lack of occurrence of $S$. disjunctus in the resident site of $S$. noricus and vice versa in spite of comparable survival rates of adult transplants of about $94 \%$ (Fig. 5), although survival usually has a larger influence on population growth rates than fertility in long-lived plants (Franco and Silvertown 2004). Even if growing sites of the two species are topographically separated-S. noricus usually inhabits flat ridges, whereas $S$. disjunctus is almost entirely restricted to north-exposed slopes-reproductive failure in the habitat of the respective other species may be an important mechanism for preventing gene flow between these reproductively strongly, but incompletely separated (based on controlled crossings; Sonnleitner et al. 2013) species. What prevents the plants from flowering is unclear; potential factors might include wind-induced mechanical stress for $S$. disjunctus at the resident side of $S$. noricus and competition by surrounding vegetationincluding tall mosses such as Hylocomium splendens and Rhytidiadelphus triquetrus - for S. noricus at the site of $S$. disjunctus. Dedicated analyses of phytohormones and other metabolites may, in the future, shed light on this hitherto neglected aspect of polyploid research. However, interpretations of the reproductive performance within our study need to be made with caution because of the strong direct effect of transplantation at least in the first year of the experiment (see "Materials and methods" section).

In a strict sense, conclusions drawn from our results should be limited to the study area, because ploidy effects cannot be statistically distinguished from population effects. Based on extensive field studies and genetic analyses, the chosen populations can be regarded as spatially (Sonnleitner et al. 2016), genetically (Winkler et al. 2017), and ecologically (Sonnleitner et al. 2010, 2016) representative for the study species as such. This is also confirmed by the initial results from transplantation experiments of adult plants from three other mountain ranges into the resident site of the same species in the study area: comparisons with the resident individuals did not reveal differences in any of the vital rates (supplementary material). Thus, we are confident that our results can be generalised to other populations within the eastern Alps.

In conclusion, our study illustrates that there may be no clear-cut answer to the question if the resident or the higher 
ploid species generally shows superior performance in polyploid complexes. Instead, our results clearly show that performance is life-history stage-dependent, and initially important species- or ploidy-intrinsic characteristics may be later outweighed by extrinsic factors, i.e., habitat selection. For instance, high-polyploid $S$. carniolicus s. str. outperformed lower ploid S. noricus and S. disjunctus with respect to seed germination and seedling growth, but this was later counteracted by higher mortality, rendering the resident species the best establisher in the long term, a pattern also reflected in adult growth and reproduction.

Acknowledgements Open access funding provided by University of Vienna. The paper is dedicated to Jan Suda, who stimulated our research into the Senecio carniolicus autopolyploid complex, and sadly passed away in March 2017. Funding was received from the Austrian Science Fund (P20736-B16 to PS followed by GMS; http://www.fwf. ac.at/). The Schwarzenberg'sche Forstverwaltung and Jacques Lemans $\mathrm{GmbH}$, St. Veit an der Glan allowed us to conduct the experiments on private property. The authors declare that they have no conflict of interest. We are grateful to J. F. Scheepens and two anonymous reviewers for their valuable comments on an earlier version of the manuscript.

Author contributions KH, PS, and GS designed the study. All authors contributed to the field work, which was led by MS. KH and MW performed the analyses. KH and PS wrote the text with further input from all authors.

Open Access This article is distributed under the terms of the Creative Commons Attribution 4.0 International License (http://creativeco mmons.org/licenses/by/4.0/), which permits unrestricted use, distribution, and reproduction in any medium, provided you give appropriate credit to the original author(s) and the source, provide a link to the Creative Commons license, and indicate if changes were made.

\section{References}

Baack EJ (2004) Cytotype segregation on regional and microgeographic scales in snow buttercups (Ranunculus adoneus: Ranunculaceae). Am J Bot 91:1783-1788. https://doi.org/10.3732/ ajb.91.11.1783

Baack EJ (2005) Ecological factors influencing tetraploid establishment in snow buttercups (Ranunculus adoneus, Ranunculaceae): minority cytotype exclusion and barriers to triploid formation. Am J Bot 92:1827-1835. https://doi.org/10.3732/ajb.92.11.1827

Baack EJ, Stanton ML (2005) Ecological factors influencing tetraploid speciation in snow buttercups (Ranunculus adoneus): niche differentiation and tetraploid establishment. Evolution 59:1936-1944. https://doi.org/10.1554/05-168.1

Bischoff A, Cremieux L, Smilauerova M, Lawson CS, Mortimer SR, Dolezal J, Lanta V, Edwards AR, Brook AJ, Macel M (2006) Detecting local adaptation in widespread grassland species- the importance of scale and local plant community. J Ecol 94:1130 1142. https://doi.org/10.1111/j.1365-2745.2006.01174.x

Bretagnolle F, Thompson JD (2001) Phenotypic plasticity in sympatric diploid and autotetraploid Dactylis glomerata. Int J Plant Sci 162:309-316. https://doi.org/10.1086/319572

Bretagnolle F, Thompson JD, Lumaret R (1995) The influence of seed size variation on seed-germination and seedling vigor in diploid and tetraploid Dactylis glomerata L. Ann Bot 76:607-615. https ://doi.org/10.1006/anbo.1995.1138

Buggs RJ, Pannell JR (2006) Rapid displacement of a monoecious plant lineage is due to pollen swamping by a dioecious relative. Curr Biol 16:996-1000. https://doi.org/10.1016/j.cub.2006.03.093

Buggs RJA, Pannell JR (2007) Ecological differentiation and diploid superiority across a moving ploidy contact zone. Evolution 61:125-140. https://doi.org/10.1111/j.1558-5646.2007.00010.x

Collins AR, Naderi R, Mueller-Schaerer H (2011) Competition between cytotypes changes across a longitudinal gradient in Centaurea stoebe (Asteraceae). Am J Bot 98:1935-1942. https://doi. org/10.3732/ajb.1100063

Comai L (2005) The advantages and disadvantages of being polyploid. Nat Rev Genet 6:836-846. https://doi.org/10.1038/nrg1711

Dona AJ, Galen C (2007) Nurse effects of alpine willows (Salix) enhance over-winter survival at the upper range limit of fireweed, Chamerion angustifolium. Arct Antarct Alp Res 39:57-64. https:// doi.org/10.1657/1523-0430(2007)39\%5B57:neoaws\%5D2.0.co;2

Duchoslav M, Šafářová L, Krahulec F (2010) Complex distribution patterns, ecology and coexistence of ploidy levels of Allium oleraceum (Alliaceae) in the Czech Republic. Ann Bot 105:719-735. https://doi.org/10.1093/aob/mcq035

Duchoslav M, Fialová M, Jandová M (2017) The ecological performance of tetra-, penta- and hexaploid geophyte Allium oleraceum in reciprocal transplant experiment may explain the occurrence of multiple-cytotype populations. J Plant Ecol 10:569-580. https:// doi.org/10.1093/jpe/rtw039

Elvebakk A, Spjelkavik S (1995) The ecology and distribution of Empetrum nigrum ssp. hermaphroditum on Svalbard and Jan Mayen. Nord J Bot 15:541-552. https://doi. org/10.1111/j.1756-1051.1995.tb00190.x

Felber-Girard M, Felber F, Buttler A (1996) Habitat differentiation in a narrow hybrid zone between diploid and tetraploid Anthoxanthum alpinum. New Phytol 133:531-540. https://doi. org/10.1111/j.1469-8137.1996.tb01921.x

Flatscher R, Escobar García P, Hülber K, Sonnleitner M, Winkler M, Saukel J, Schneeweiss GM, Schönswetter P (2015) Underestimated diversity in one of the world's best studied mountain ranges: the polyploid complex of Senecio carniolicus (Asteraceae) contains four species in the European Alps. Phytotaxa 213:1-21. https://doi.org/10.11646/phytotaxa.213.1.1

Flegrová M, Krahulec F (1999) Anthoxanthum odoratum and A. alpinum: life history parameters at two different altitudes. Folia Geobot 34:19-31. https://doi.org/10.1007/bf02803074

Franco M, Silvertown J (2004) A comparative demography of plants based upon elasticities of vital rates. Ecology 85:531-538. https ://doi.org/10.1890/02-0651

Gams H (1931) Die klimatische Begrenzung von Pflanzenarealen und die Verbreitung der hygrischen Kontinentalität in den Alpen. Zeitschrift der Gesellschaft für Erdkunde, Berlin

Glennon KL, Ritchie ME, Segraves KA (2014) Evidence for shared broad-scale climatic niches of diploid and polyploid plants. Ecol Lett 17:574-582. https://doi.org/10.1111/ele.12259

Godsoe W, Larson MA, Glennon KL, Segraves KA (2013) Polyploidization in Heuchera cylindrica (Saxifragaceae) did not result in a shift in climatic requirements. Am J Bot 100:496-508. https://doi. org/10.3732/ajb.1200275

Hahn MA, van Kleunen M, Müller-Schärer H (2012) Increased phenotypic plasticity to climate may have boosted the invasion success of polyploid Centaurea stoebe. PLoS One 7:e50284. https://doi. org/10.1371/journal.pone.0050284

Halekoh U, Højsgaard S, Yan J (2006) The R package geepack for generalized estimating equations. J Stat Softw 15:1-11

Hülber K, Sonnleitner M, Flatscher R, Berger A, Dobrovsky R, Niessner S, Nigl T, Schneeweiss GM, Kubešová M, Rauchová J, Suda J, Schönswetter P (2009) Ecological segregation drives fine-scale 
cytotype distribution of Senecio carniolicus in the Eastern Alps. Preslia 81:309-319

Hülber K, Sonnleitner M, Suda J, Krejčíková J, Schönswetter P, Schneeweiss GM, Winkler M (2015) Ecological differentiation, lack of hybrids involving diploids, and asymmetric gene flow between polyploids in narrow contact zones of Senecio carniolicus (syn. Jacobaea carniolica, Asteraceae). Ecol Evol 5:1224-1234. https ://doi.org/10.1002/ece3.1430

Johnson MTJ, Husband BC, Burton TL (2003) Habitat differentiation between diploid and tetraploid Galax urceolata (Diapensiaceae). Int J Plant Sci 164:703-710. https://doi.org/10.1086/376813

Kirchheimer B, Schinkel CCF, Dellinger AS, Klatt S, Moser D, Winkler M, Lenoir J, Caccianiga M, Guisan A, Nieto-Lugilde D, Svenning J-C, Thuiller W, Vittoz P, Willner W, Zimmermann NE, Hörandl E, Dullinger S (2016) A matter of scale: apparent niche differentiation of diploid and tetraploid plants may depend on extent and grain of analysis. J Biogeogr 43:716-726. https:// doi.org/10.1111/jbi.12663

Koláŕ F, Čertner M, Suda J, Schönswetter P, Husband BC (2017) Mixed-ploidy species: progress and opportunities in polyploid research. Trends Plant Sci 22:1041-1055. https://doi. org/10.1016/j.tplants.2017.09.011

Körner C (2003) Alpine plant life-functional plant ecology of high mountain ecosystems, 2nd edn. Springer, Heidelberg

Levin DA (1975) Minority cytotype exclusion in local plant populations. Taxon 24:35-43. https://doi.org/10.2307/1218997

Levin D (1983) Polyploidy and novelty in flowering plants. Am Nat 122:1-25. https://doi.org/10.1086/284115

Levin DA (2002) The role of chromosomal change in plant evolution. Oxford University Press, New York

Lumaret R, Guillerm JL, Delay J, Ait Lhaj Loutfi A, Izco J, Jay M (1987) Polyploidy and habitat differentiation in Dactylis glomerata L. from Galicia (Spain). Oecologia 73:436-446. https://doi. org/10.1007/BF00385262

Maceira NO, Jacquard P, Lumaret R (1993) Competition between diploid and derivative autotetraploid Dactylis glomerata L. from Galicia. Implications for the establishment of novel polyploid populations. New Phytol 124:321-328. https://doi. org/10.1111/j.1469-8137.1993.tb03822.x

Manzaneda AJ, Rey PJ, Bastida JM, Weiss-Lehman C, Raskin E, Mitchell-Olds T (2012) Environmental aridity is associated with cytotype segregation and polyploidy occurrence in Brachypodium distachyon (Poaceae). New Phytol 193:797-805. https://doi.org/1 0.1111/j.1469-8137.2011.03988.x

Martin SL, Husband BC (2013) Adaptation of diploid and tetraploid Chamerion angustifolium to elevation but not local environment. Evolution 67:1780-1791. https://doi.org/10.1111/evo.12065

McIntyre PJ (2012) Polyploidy associated with altered and broader ecological niches in the Claytonia perfoliata (Portulacaceae) species complex. Am J Bot 99:655-662. https://doi.org/10.3732/ ajb.1100466

McIntyre PJ, Strauss S (2017) An experimental test of local adaptation among cytotypes within a polyploid complex. Evolution 71:1960-1969. https://doi.org/10.1111/evo.13288

Mitchell RJ, Irwin RE, Flanagan RJ, Karron JD (2009) Ecology and evolution of plant-pollinator interactions. Ann Bot 103:13551363. https://doi.org/10.1093/aob/mcp122

Mráz P, Španiel S, Keller A, Bowmann G, Farkas A, Šingliarová B, Rohr RP, Broennimann O, Müller-Schärer H (2012) Anthropogenic disturbance as a driver of microspatial and microhabitat segregation of cytotypes of Centaurea stoebe and cytotype interactions in secondary contact zones. Ann Bot 110:615-627. https ://doi.org/10.1093/aob/mcs120

Otto SP (2007) The evolutionary consequences of polyploidy. Cell 131:452-462. https://doi.org/10.1016/j.cell.2007.10.022
Otto SP, Whitton J (2000) Polyploid incidence and evolution. Annu Rev Genet 34:401-437. https://doi.org/10.1146/annurev.genet .34.1.401

Parisod C, Holderegger R, Brochmann C (2010) Evolutionary consequences of autopolyploidy. New Phytol 186:5-17. https://doi.org /10.1111/j.1469-8137.2009.03142.x

Petit C, Bretagnolle F, Felber F (1999) Evolutionary consequences of diploid-polyploid hybrid zones in wild species. Tree 14:306-311. https://doi.org/10.1016/S0169-5347(99)01608-0

R Development Core Team (2016) A language and environment for statistical computing. R Foundation for Statistical Computing, Vienna

Raabová J, Fischer M, Münzbergová Z (2008) Niche differentiation between diploid and hexaploid Aster amellus. Oecologia 158:463472. https://doi.org/10.1007/s00442-008-1156-1

Ramsey J (2011) Polyploidy and ecological adaptation in wild yarrow. Proc Natl Acad Sci USA 108:7096-7101. https://doi.org/10.1073/ pnas. 1016631108

Ramsey J, Ramsey TS (2014) Ecological studies of polyploidy in the 100 years following its discovery. Philos Trans R Soc B 369:20130352. https://doi.org/10.1098/rstb.2013.0352

Ramsey J, Schemske DW (2002) Neopolyploidy in flowering plants. Annu Rev Ecol Syst 33:589-639. https://doi.org/10.1146/annur ev.ecolysis.33.010802.150437

Sagarin RD, Gaines SD (2002) The 'abundant centre' distribution: to what extent is it a biogeographical rule? Ecol Lett 5:137-147. https://doi.org/10.1046/j.1461-0248.2002.00297.x

Schönswetter P, Lachmayer M, Lettner C, Prehsler D, Rechnitzer S, Reich DS, Sonnleitner M, Wagner I, Hülber K, Schneeweiss GM, Trávníček P, Suda J (2007) Sympatric diploid and hexaploid cytotypes of Senecio carniolicus (Asteraceae) in the Eastern Alps are separated along an altitudinal gradient. J Plant Res 120:721-725. https://doi.org/10.1007/s10265-007-0108-X

Soltis DE, Albert VA, Leebens-Mack J, Bell CD, Paterson AH, Zheng CF, Sankoff D, dePamphilis CW, Wall PK, Soltis PS (2009) Polyploidy and angiosperm diversification. Am J Bot 96:336-348. https://doi.org/10.3732/ajb.0800079

Soltis DE, Buggs RJA, Doyle JJ, Soltis PS (2010) What we still don't know about polyploidy. Taxon 59:1387-1403

Sonnleitner M, Flatscher R, Escobar García P, Rauchová J, Suda J, Schneeweiss GM, Hülber K, Schönswetter P (2010) Distribution and habitat segregation on different spatial scales among diploid, tetraploid and hexaploid cytotypes of Senecio carniolicus (Asteraceae) in the Eastern Alps. Ann Bot 106:967-977. https://doi. org/10.1093/aob/mcq192

Sonnleitner M, Weis B, Flatscher R, Escobar García P, Suda J, Krejčíková J, Schneeweiss GM, Winkler M, Schönswetter P, Hülber K (2013) Parental ploidy strongly affects offspring fitness in heteroploid crosses among three cytotypes of autopolyploid Jacobaea carniolica (Asteraceae). PLoS One 8:e78959. https:// doi.org/10.1371/journal.pone.0078959

Sonnleitner M, Hülber K, Flatscher R, Escobar García P, Winkler M, Suda J, Schönswetter P, Schneeweiss GM (2016) Ecological differentiation of diploid and polyploid cytotypes of Senecio carniolicus sensu lato (Asteraceae) is stronger in areas of sympatry. Ann Bot 117:269-276. https://doi.org/10.1093/aob/mcv176

Ståhlberg D, Hedrén M (2009) Habitat differentiation, hybridization and gene flow patterns in mixed populations of diploid and autotetraploid Dactylorhiza maculata s.1. (Orchidaceae). Evol Ecol 23:295-328. https://doi.org/10.1007/s10682-007-9228-y

Stebbins GL (1971) Chromosomal evolution in higher plants. Edward Arnold, London

Suda J, Weiss-Schneeweiss H, Tribsch A, Schneeweiss GM, Trávníček P, Schönswetter P (2007) Complex distribution patterns of di-, tetra-, and hexaploid cytotypes in the European high mountain 
plant Senecio carniolicus (Asteraceae). Am J Bot 94:1391-1401. https://doi.org/10.3732/ajb.94.8.1391

te Beest M, Le Roux JJ, Richardson DM, Brysting AK, Suda J, Kubešová M, Pyšek P (2012) The more the better? The role of polyploidy in facilitating plant invasions. Ann Bot 109:19-45. https://doi.org/10.1093/aob/mcr277

Therneau T (2015) A Package for survival analysis in S. version 2.38. https://CRAN.R-project.org/package=survival. Accessed 12 July 2018

Thompson JD, Lumaret R (1992) The evolutionary dynamics of polyploid plants—origins, establishment and persistence. Tree 7:302307. https://doi.org/10.1016/0169-5347(92)90228-4

Thompson KA, Husband BC, Maherali H (2014) Climatic niche differences between diploid and tetraploid cytotypes of Chamerion angustifolium (Onagraceae). Am J Bot 101:1868-1875. https:// doi.org/10.3732/ajb.1400184
Turner H (1958) Maximaltemperaturen oberflächennaher Bodenschichten an der alpinen Waldgrenze. Wetter Leben 10:1-12

Wakonigg H (1978) Witterung und Klima in der Steiermark. Verlag für die Technische Universität, Graz

Weiss-Schneeweiss H, Emadzade K, Jang TS, Schneeweiss GM (2013) Evolutionary consequences, constraints and potential of polyploidy in plants. Cytogenet Genome Res 140:137-150. https:// doi.org/10.1159/000351727

Winkler M, Escobar García P, Gattringer A, Sonnleitner M, Hülber K, Schönswetter P, Schneeweiss GM (2017) A novel method to infer the origin of polyploids from amplified fragment length polymorphism data reveals that the alpine polyploid complex of Senecio carniolicus (Asteraceae) evolved mainly via autopolyploidy. Mol Ecol Resour 17:877-892. https://doi. org/10.1111/1755-0998.12641 